\title{
Study on Mechanical Properties and Damage Evolution of High-Porosity Concrete under Cyclic Loading and Unloading
}

\author{
Dong Zhang, ${ }^{1}$ Ai-hong Lu $\left(\mathbb{D},{ }^{2}\right.$ Xia Wang, ${ }^{1}$ Yu Xia, ${ }^{2}$ Si-yu Gong, ${ }^{1}$ Lei Sun, ${ }^{3}$ Ran-fang Zuo, ${ }^{1}$ \\ and Yang Dong ${ }^{1}$ \\ ${ }^{1}$ National Institute of Clean-and-Low-Carbon Energy, Beijing 102211, China \\ ${ }^{2}$ School of Mechanics and Civil Engineering, China University of Mining and Technology, Xuzhou 221116, China \\ ${ }^{3}$ State Key Laboratory of Coal Resources and Safe Mining, China University of Mining and Technology, Xuzhou 221116, China \\ Correspondence should be addressed to Ai-hong Lu; xzlah@163.com
}

Received 13 October 2021; Accepted 3 November 2021; Published 19 November 2021

Academic Editor: Ma Jianjun

Copyright (c) 2021 Dong Zhang et al. This is an open access article distributed under the Creative Commons Attribution License, which permits unrestricted use, distribution, and reproduction in any medium, provided the original work is properly cited.

Understanding the mechanical properties and energy response of high-porosity concrete under the cyclic loading and unloading is the foundation of road construction in sponge city. In this study, the concrete with the porosity of $15 \%$ was taken as the research object, and the cyclic loading and unloading tests on the high-porosity concrete were performed under the stress amplitude of $25 \mathrm{MPa}, 30 \mathrm{MPa}$, and $35 \mathrm{MPa}$ in the elastic stage. The effects of stress amplitude and cycle number on the mechanical characteristics and damage evolution law of concrete were obtained. The experimental results show the following. (1) With the increase of cycle number, the loading and unloading elastic modulus of concrete under different stress amplitudes first increases and then decreases; the greater the stress amplitude, the faster the growth and deceleration of the loading and unloading elastic modulus. (2) With the increase of the cycle number, the peak strain and residual plastic deformation increase. (3) The greater the stress amplitude, the higher the damage of concrete; with the increasing number of cyclic loading and unloading, the damage of concrete is enhanced gradually. When the damage variable value is 1 , the relationship between the cycle number and the initial stress amplitude satisfies a negative exponential function.

\section{Introduction}

Sponge city construction is an important opportunity and challenge in China's new urbanization construction, and it is also an important way to solve the water shortage, water environment deterioration, and flood disasters in the current new urbanization construction [1]. Due to the good permeability of permeable concrete, permeable concrete has been widely used in the construction of sponge cities [2]. The application of permeable concrete not only meets the needs of environmental protection but also effectively utilizes urban water resources and alleviates the urban heat island effect $[1,3]$.

At present, the effect of loading mode on the mechanical properties of concrete has been extensively studied [4]. Cook and Chindaprasirt [5] investigated the effect of loading history on the compressive properties of concrete. It is found that the compressive performance of concrete is slowly rising in the early stage; after reaching a certain strength (about $10 \%$ of the theoretical value), the compressive performance of concrete decreases rapidly with the occurrence of damage. Subsequently, Cook and Chindaprasirt [6] explored the effect of loading history on the tensile properties of concrete. Akutagawa et al. [7] found that the loading history on the compressive performance of concrete not only affects its compressive performance but also affects the elastic modulus and Poisson's ratio of concrete. Through the MTS 815 program-controlled servo test system, Xing et al. [8] conducted a uniaxial compression test on concrete cylindrical specimens under cyclic loads and studied the effects of the initial load, cyclic frequency, and the increased amplitude of cyclic stress on the mechanical behavior of concrete specimens. It is concluded that under the same initial load and increased amplitude of cyclic stress, cyclic 
frequency has little effect on the strength of concrete. Under the same initial load and cycle frequency, the strength of the specimen decreases with the increase of the increased amplitude of cyclic stress. Under the same cycle frequency and the same increased amplitude of cyclic stress, the strength of concrete tends to decrease with the increase of initial load [9]. By using a large multifunctional dynamic and static triaxial apparatus, $\mathrm{Hu}$ et al. [10], Wang et al. [11], and Liang et al. [12] treated the damage characteristics as the research objective, analyzed the constitutive model of concrete under cyclic load, and then obtained the damage law. According to the research result of Song et al. [13], concrete will have much more fatigue strain under cyclic load than monotonic load. They also found that the damage accumulation caused by internal microcrack is the result of the irreversible deformation of concrete material and the change of various mechanical parameters [14]. Song et al. $[13,15]$ analyzed the destruction of concrete under cyclic load in the way of the hysteretic characteristics of dissipated energy. They also researched the failure mode of concrete under monotonic load and cyclic load and then found that the size and type of crack are directly related to the loading method. At the same time, the energy loss during loading increases with the increase of load level and simultaneously reaches the maximum. Ma et al. [16] studied the crushing characteristics and seepage characteristics of gangue concrete samples under different stresses and proposed a method to predict the evolution of permeability using fractal dimensions. Jiang et al. [17] compared and analyzed the fatigue damage characteristics of concrete through three types of cyclic action of concrete and evaluated the fatigue life based on the damage variables. Xiao et al. [18] established a damage accumulation model with mathematical equation and physical significance for rock under cyclic load and verified it with data.

Scholars have used different experimental methods to study the relationship between porosity and physical and mechanical properties of concrete and achieved rich results [19-25]. Balshin [22] and Hasselman and Fulrath [23] investigated the influence of porosity change on compressive strength of the porous concrete through experiments and obtained the relationship between compressive strength and porosity change. Knudsen [24] conducted a series of seepage experiments to explore the influence of fluid scouring behavior on sample porosity and permeability. Ma et al. [26] explored the relationship between porosity and compressive strength of cement foamed concrete and developed a mathematical model to describe the relationship between porosity and strength of concrete. Deng and Li [27] adopted expanded polystyrene (EPS) particles with a diameter of about $1-2 \mathrm{~mm}$ as the approximate pore structure in concrete and obtained the compressive strength, splitting tensile strength, and static compressive elastic modulus of C15, $\mathrm{C} 20$, and C30 concrete with the porosity of $0,1 \%, 3 \%$, and $5 \%$. It is reported that under the same strength grade, the compressive strength, split tensile strength, and static compressive elastic modulus of concrete decrease with the increase of porosity. Xia et al. [28] discussed the influence of porosity on the energy dissipation of artificial rock from the perspective of impact load and found that under the action of impact load, the energy dissipated by concrete increases with the increase of concrete porosity.

In the research on the mechanical properties of concrete, mechanical properties of concrete with different porosity under uniaxial compression are mainly studied, as well as the concrete test without considering the porosity factor. However, the roads of sponge cities are constructed on highporosity permeable concrete, and vehicles have a typical cyclic loading and unloading effect on the roads. At present, there are few studies on the mechanical properties of highporosity concrete under cyclic load [29]. To this end, the experimental method was used to analyze the effects of cyclic number, cyclic load amplitude, and other parameters on the mechanical properties and energy dissipation of high-porosity concrete in this study.

\section{Test Equipment and Test Scheme}

2.1. Sample Preparation. The raw materials of concrete samples in this test were cement, stone, and water. The PO 32.5 grade ordinary Portland cement was produced by Xuzhou China United Cement Corporation. The limestone gravel with the particle size of $5-13 \mathrm{~mm}$ was used as coarse aggregate. The apparent density of limestone gravel was $3010 \mathrm{Kg} / \mathrm{m}^{3}$, the content of elongated and flaky particles was $5.25 \%$, the mud content was $0.26 \%$, and the water content was $0.24 \%$.

The cubic concrete samples with high porosity of $P=15 \%$ and the size of $100 \mathrm{~mm} \times 100 \mathrm{~mm} \times 100 \mathrm{~mm}$ were prepared. According to the previous studies [30], the mixed proportion of water, cement, and stone was determined. Then, concrete mixed by the mixer was injected into the mold, and the surface was smoothed after shaking by the shaking table. The concrete was cured in the curing room (temperature $20 \pm 2^{\circ} \mathrm{C}$ ) for $24-48$ hours and watered every 8 hours. After that, the mold was removed, and the demoulded concrete was placed in the curing room (temperature $20 \pm 2^{\circ} \mathrm{C}$, humidity $\geq 95 \%$ ) and cured for 28 days. Figure 1 shows a part of the processed concrete samples. The water saturation method was used to remove the specimens that did not meet the porosity requirement. Finally, 40 pieces of specimens were processed for the subsequent study.

2.2. Experimental Equipment. The universal testing machine of the State Key Laboratory for Geomechanics and Deep Underground Engineering of China University of Mining and Technology was used as the loading equipment in the test. This system consists of four parts: control valve system, dynamic loading system, data acquisition system, and computer control system. The data acquisition system consists of two parts. One is the displacement load acquisition system carried by the test loading equipment; the other part is the ASMB2-8 super static signal acquisition instrument. Figure 2 shows the main test instruments. During the test, horizontal and vertical strain gauges were attached to the side of the sample, as shown in Figure 2. 


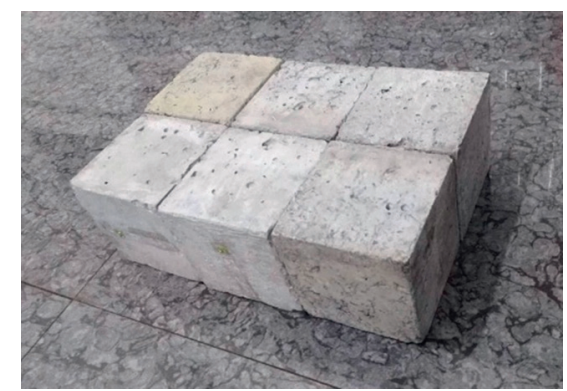

Figure 1: Processed concrete samples.

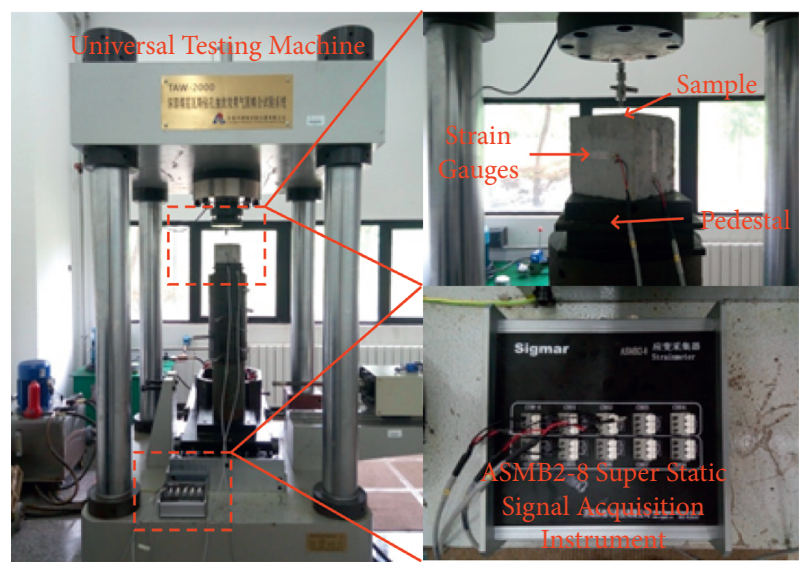

FIGURE 2: Test instrument diagram.

2.3. Test Scheme. Firstly, the uniaxial compression test of high-porosity concrete was carried out, and its full stressstrain curve was obtained, as shown in Figure 3. Secondly, the deformation process of high-porosity concrete was divided into different stages: (I) initial compaction process $\left(\left(\mathrm{d}^{2} \sigma / \mathrm{d} \varepsilon^{2}\right)>0\right)$, (II) approximate linear elastic stage $\left(\left(\mathrm{d}^{2} \sigma / \mathrm{d} \varepsilon^{2}\right)=0\right)$, (III) microcrack evolution stage $\left(\left(\mathrm{d}^{2} \sigma / \mathrm{d} \varepsilon^{2}\right)<0\right)$, and (IV) failure stage $((\mathrm{d} \sigma / \mathrm{d} \varepsilon)<0)$.

In the test, $50 \%, 60 \%$, and $70 \%$ of the peak stress of concrete under uniaxial compression, i.e., $25 \mathrm{MPa}, 30 \mathrm{MPa}$, and $35 \mathrm{MPa}$, were selected as the stress amplitude of low cyclic loading. The three stress amplitudes were in the approximate linear elastic stage (stage II) in Figure 3. During the test, the corresponding stress amplitudes were loaded by $0.002 \mathrm{~mm} / \mathrm{s}$ displacement loading and then unloaded to $5 \mathrm{MPa}$ (the boundary point between compaction stage and linear elastic stage) by $0.002 \mathrm{~mm} / \mathrm{s}$ displacement unloading. This process was called a cycle. A total of 60 cycles were performed under the stress amplitude of each group to analyze the influence of stress amplitude $\sigma_{M}$ and cycle number $C$ on the mechanical properties and damage evolution of concrete.

\section{Mechanical Properties of High-Porosity Concrete under Different Stress Amplitudes in Cyclic Loading and Unloading}

3.1. Variation Law of Stress-Strain Curve with Stress Amplitude. Figure 4 shows the similarities and differences of concrete stress-strain curves under cyclic loading and unloading with different stress amplitudes. With the increase of the cycle number, the peak strain and residual plastic deformation under different stress amplitudes gradually increase. However, the changes of peak strain and residual plastic deformation under different stress amplitudes are different. The greater the stress amplitude, the larger the increase of the residual plastic deformation and the peak strain. When the stress amplitude is $30 \mathrm{MPa}$ and $35 \mathrm{MPa}$, the density of the stress-strain cycle curve changes from sparse to dense and then to sparse, while when the stress amplitude is $25 \mathrm{MPa}$, the density of the stress-strain cycle curve changes from sparse to dense. This is can be explained as follows. Before loading, there are original pores and cracks in the high-porosity concrete, and the concrete is more prone to deformation; under the action of the load, these pores and cracks are gradually and partially closed, leading to the denser concrete. Thus, the stress-strain cycle curve shows a process from sparse to dense. When the concrete undergoes multiple cyclic loading and unloading, internal pores of the concrete are damaged, leading to the generation of new cracks. At the same time, coupled with the development of the original cracks, the integrity of the internal structure of concrete becomes worse and the compressive capacity becomes weaker. Thus, the stress-strain cycle curve changes from dense to sparse. When the stress amplitude is $25 \mathrm{MPa}$, there is no change from dense to sparse in stress-strain cycle curves. It indicates that the internal structure of the sample is relatively complete after 60 cyclic loading and unloading cycles at the stress amplitude of $25 \mathrm{MPa}$. Besides, the concrete can generally withstand the action of multiple alternating loads if the applied load is relatively small.

3.2. Variation Law of Mechanical Properties of Concrete with Stress Amplitude. Under different loading stress amplitudes and number of cycles, the variation laws of different loading stress amplitudes and cycle number on the loading elastic modulus EF, unloading elastic modulus EC, and peak strain $\varepsilon_{F}$ and residual plastic deformation $\varepsilon_{C}$ (the strain corresponding to unloading to $5 \mathrm{MPa}$ during unloading) of the concrete are shown in Figure 5.

After the concrete is loaded, the initial microcrack will expand. When the load is small, the length and width of the initial interface crack will increase and form a new interface crack. As long as the load does not exceed a certain value, the crack will stop expanding due to constant load or unloading. However, when cyclic loading is repeated, the crack will continue to expand and the mechanical properties of the concrete will be changed; the greater the applied load, the faster the crack propagation. Therefore, when concrete is subjected to cyclic loading, its mechanical properties will be changed accordingly.

As shown in Figures 5(a) and 5(b), the influence of stress amplitude and cycle number on loading and unloading elastic modulus can be obtained. Under the same stress amplitude, the loading elastic modulus and unloading elastic modulus first rise and then decline with the increase of cycle number. The greater the stress amplitude, the faster the rising rate and the faster the decline rate. When the stress 


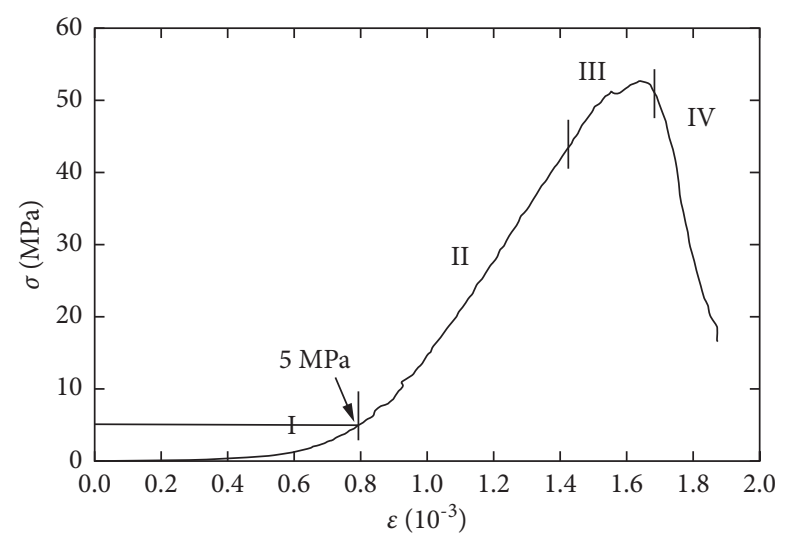

FIGURE 3: Stress-strain curve segmentation of high-porosity concrete.

amplitude is $25 \mathrm{MPa}, 30 \mathrm{MPa}$, and $35 \mathrm{MPa}$, there are different cycle numbers required for reaching the peak of loading and unloading elastic modulus. The cycle numbers of 55, 35, and 15 are required for the peak of loading elastic modulus, and the cycle numbers of 50,30, and 15 are required for the peak of unloading elastic modulus, respectively. In other words, the greater the stress amplitude, the less the cycle number required for the maximum of loading and unloading elastic modulus. When the stress amplitude is $25 \mathrm{MPa}$ and $35 \mathrm{MPa}$, the maximum values of loading elastic modulus are $59.07 \mathrm{GPa}$ and $58.12 \mathrm{GPa}$, respectively, and the maximum values of unloading elastic modulus are $63.71 \mathrm{GPa}$ and $64.2 \mathrm{GPa}$, respectively. Therefore, the larger the stress amplitude, the smaller the maximum value of loading elastic modulus and the larger the maximum value of unloading elastic modulus.

Figures 5(c) and 5(d) show the influence of stress amplitude and cycle number on peak strain and residual plastic deformation. It can be concluded that the greater the stress amplitude, the greater the corresponding peak strain and residual plastic deformation at the same cycle number. With the increase of the cycle number, the peak strain and residual plastic deformation under the three stress amplitudes linearly increase. Under different stress amplitudes, there are different increasing rates of peak strain and residual plastic deformation with the increase of cycle number. When the stress amplitude is $35 \mathrm{MPa}$, the increasing rate of peak strain and residual plastic deformation is the largest with the increase of cycle number; when the stress amplitude is $25 \mathrm{MPa}$, the increasing rate is the smallest.

\section{Damage Evolution Law of High- Porosity Concrete}

4.1. Definition of Damage Variable. High-porosity concrete is an elastic-plastic material. In the process of cyclic loading and unloading, the damage evolution process of concrete is closely related to the strain amplitude of concrete and cycle number [31]. Under the same stress amplitude, the unloading process is a slow process. Only when the damage threshold of porosity accumulation is reached after a certain number of cycles, the mechanical properties of the concrete during the unloading process will be attenuated. Before attenuation, in each cycle, the strength and elastic modulus of concrete may be greater than or equal to the initial elastic modulus of concrete. At this time, if the damage of concrete is defined according to the traditional elastic modulus method, the damage variable will be negative or the damage variable will be 0 .

Therefore, the previous definition of damage to elastic materials is not applicable in this study, and a new definition of damage is introduced for the elastic-plastic body. For a single cycle of concrete, the deformation modulus at the damage is

$$
\widetilde{E}=\frac{\sigma}{\varepsilon}
$$

At this time, the unloading stiffness $E_{C}$ is expressed as follows:

$$
E_{c}=\frac{\sigma}{\varepsilon-\varepsilon_{c}} .
$$

The deformation modulus at the damage can be reexpressed as

$$
\widetilde{E}=\frac{\varepsilon-\varepsilon_{c}}{\varepsilon} E_{c}
$$

Then, the damage modulus of concrete under the final cycle can be expressed as

$$
D=1-\frac{\varepsilon-\varepsilon_{C}}{\varepsilon}\left(\frac{E_{C}}{E}\right),
$$

where $\varepsilon$ and $\varepsilon_{C}$ are the peak strain and residual strain and $E_{F}$ and $E_{C}$ are the loading elastic modulus and unloading elastic modulus, respectively.

Under cyclic loading, the damage variable of concrete is a function of the cycle number, stress amplitude, and strain amplitude. When analyzing the damage change of concrete, it is necessary to consider the loading mode and the cycle number of concrete. By combining the mechanical parameters of concrete under cyclic load, the internal damage of concrete can be analyzed. 


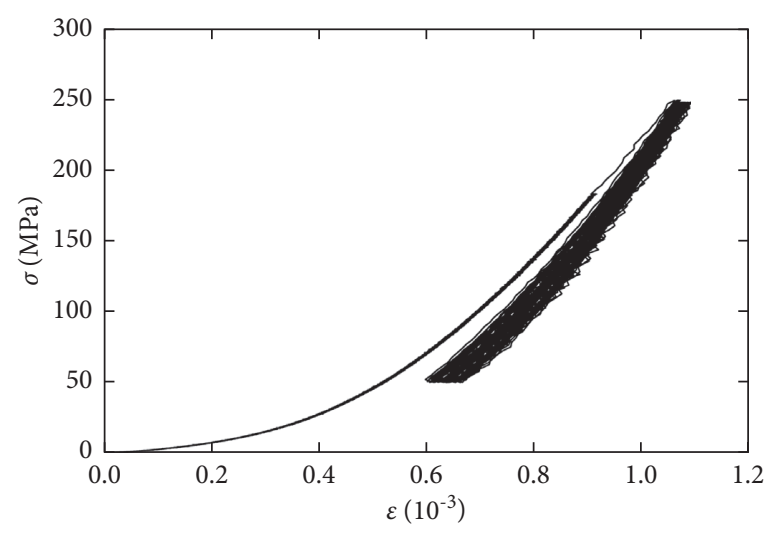

(a)

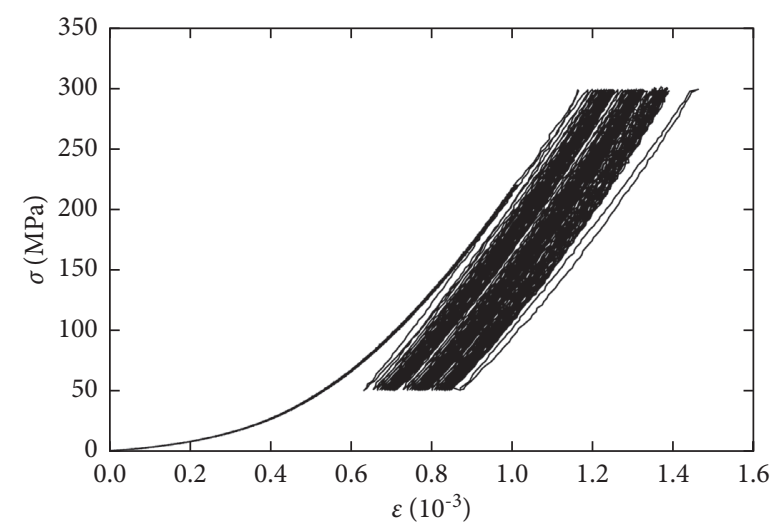

(b)

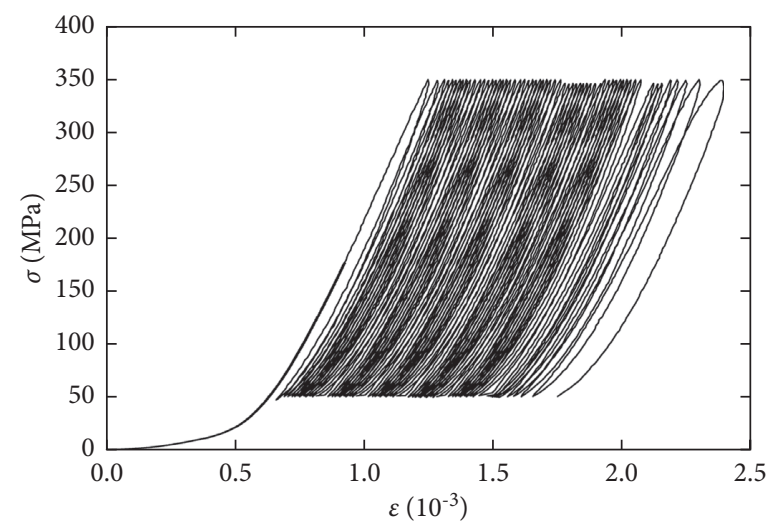

(c)

FIGURE 4: Stress-strain curves of concrete under cyclic loading with different stress amplitudes. (a) $\sigma_{M}=25 \mathrm{MPa}$. (b) $\sigma_{M}=30 \mathrm{MPa}$. (c) $\sigma_{M}=35 \mathrm{MPa}$.

4.2. Study on Damage of Concrete under Cyclic Loading and Unloading. Figure 6 shows the variation law of the damage variable of the concrete with the number of cycles under different stress amplitudes. As shown in Figure 6, the change law of concrete damage variables with the cycle number under four different stress amplitudes is mainly reflected in the following aspects: (1) under the same stress amplitude, the damage of concrete gradually increases with the increase of the cycle number; (2) with the same number of cycles, the damage variable of concrete under the large stress amplitude is generally greater than that under the small stress amplitude. After 5 cycles, the damage variable of concrete under the stress amplitude of $38 \mathrm{MPa}$ is 0.37 , while the damage variable of concrete under the stress amplitude of $25 \mathrm{MPa}$ is 0.33 .

The damage variable gradually increases with the increase of the cycle number, which indicates that the internal damage of concrete is a cumulative process. The increase of the cycle number leads to the gradual maturity of the development of internal cracks in concrete. Many cracks cannot be closed after unloading and develop to the surrounding space during the reloading. The larger the stress amplitude, the more obvious the effect. follows:

$$
\begin{aligned}
& 25 \mathrm{MPa}: D=0.0037 C+0.3144 . R=0.9884, \\
& 30 \mathrm{MPa}: D=0.004 C+0.339 . R=0.959 \\
& 35 \mathrm{MPa}: D=0.0046 C+0.3434 . R=0.9846
\end{aligned}
$$

When the damage variable value is set as 1 , the number of cyclic loading required for the failure of concrete samples can be roughly estimated. Through calculation, 185 cycles of cyclic loading are required for the sample failure under the stress amplitude of $25 \mathrm{MPa}, 166$ cycles under $30 \mathrm{MPa}, 142$ cycles under $35 \mathrm{MPa}$, and 131 cycles under $38 \mathrm{MPa}$.

4.3. Service Life Prediction of High-Porosity Concrete under Cyclic Loading and Unloading. Due to the limitation of test conditions and the long cycle time of cyclic loading and unloading, the relationship between the cycle number and damage variables can be fitted through effective test data, and the cycle number can be obtained when the damage variable value of the sample is 1 under different stress amplitudes. When the damage variable of cyclic loading and unloading is set as 1 , the cycle number under the stress amplitudes of $25 \mathrm{MPa}$ and $30 \mathrm{MPa}$ is obtained through calculation of equations (5)-(7). In this way, the relationship with the stress amplitude can be 


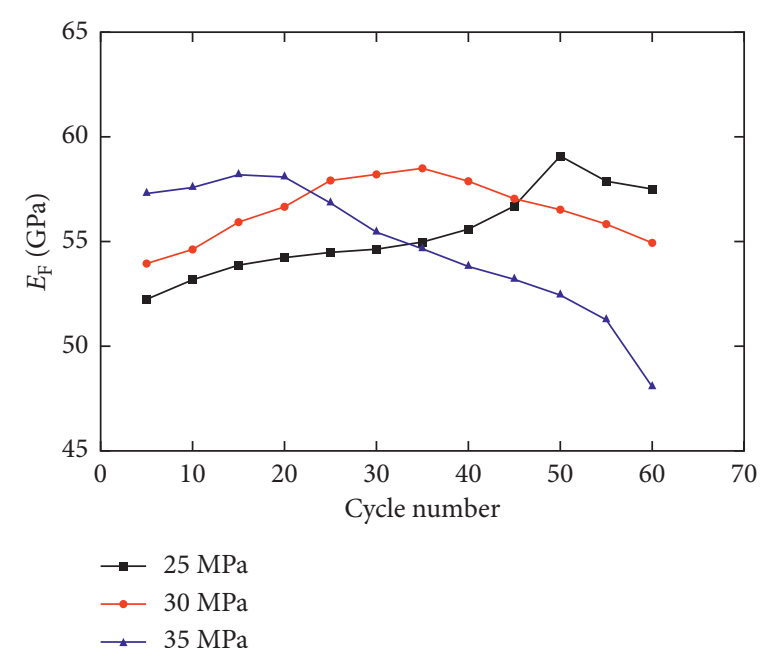

(a)

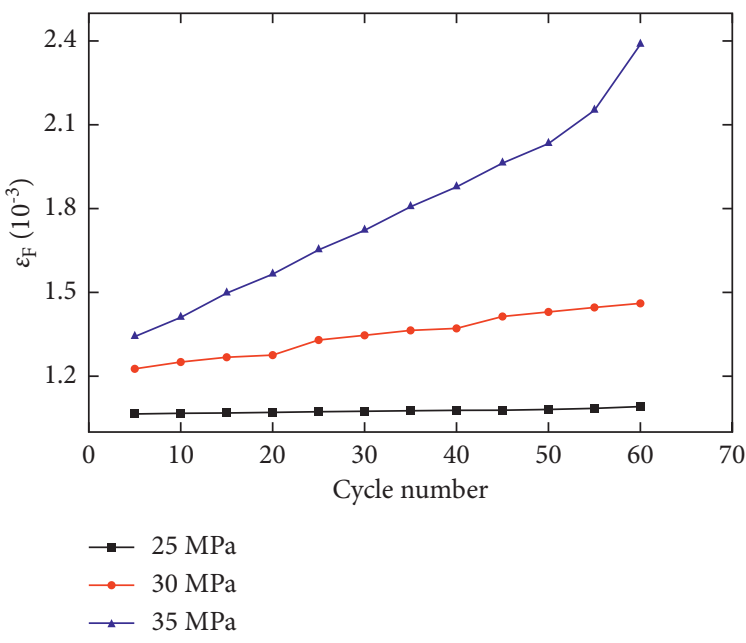

(c)

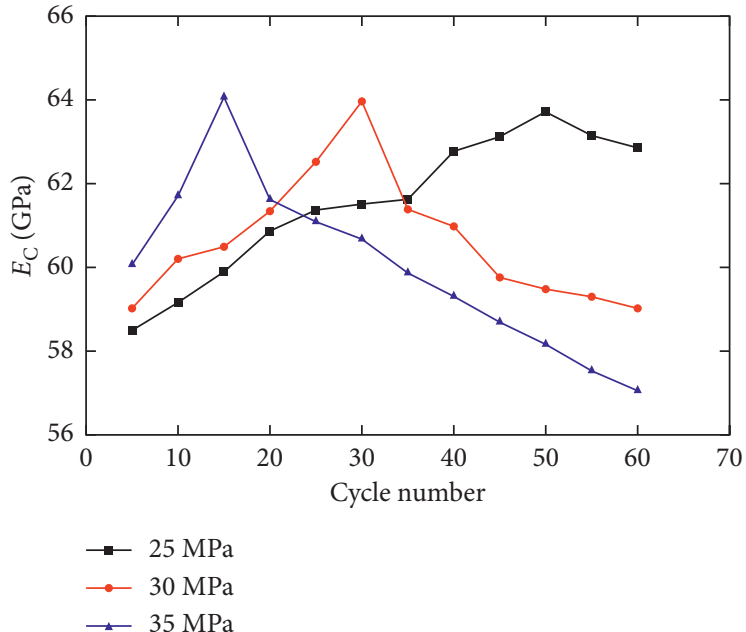

(b)

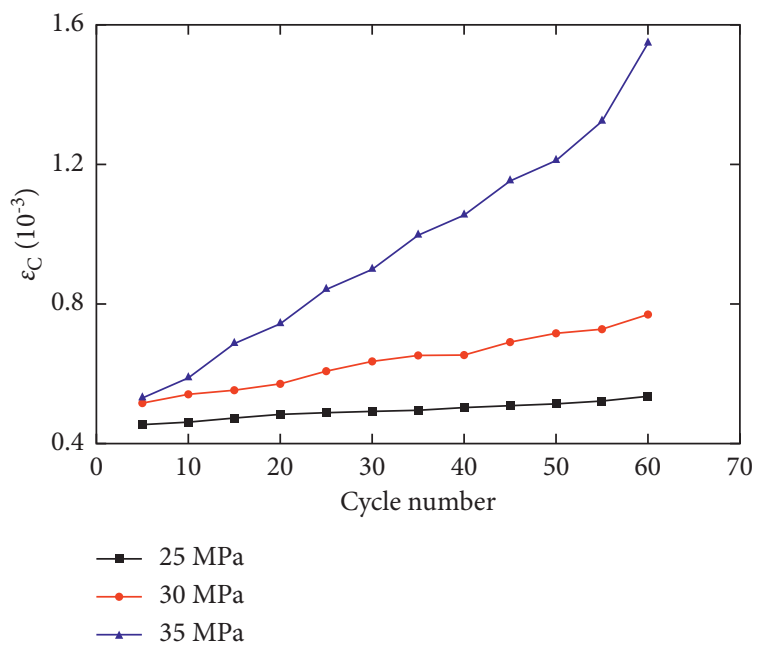

(d)

Figure 5: Variation law of mechanical properties of concrete under different stress amplitudes. (a) Variation law of loading elastic modulus $E_{F}$ of concrete with the cycle number $C$ under different stress amplitudes. (b) Variation law of unloading elastic modulus $E_{C}$ of concrete with the cycle number $C$ under different stress amplitudes. (c) Variation law of peak strain $\varepsilon_{F}$ of concrete with the cycle number $C$ under different stress amplitudes. (d) Variation law of residual plastic deformation $\varepsilon_{C}$ of concrete with the cycle number $C$ under different stress amplitudes.

established by the number of cycles when the damage variable is 1. To intuitively clarify the relationship between the damage variable of concrete and the initially applied uniaxial stress, the relationship curve between the cycle number of concrete and the stress amplitude is shown in Figure 7.

As can be seen from Figure 6, with the gradual increase of the initially applied stress, the cycle number of concrete gradually decreases. By linear fitting the initially applied stress and the cycle number, the variation law can be obtained as follows:

$$
C=2 \times 10^{8} \mathrm{e}^{-0.342 \sigma_{M}}, \quad R^{2}=0.9489 .
$$

When the stress value of $54 \mathrm{MPa}$ is substituted into equation (8), it is found that the cycle number is less than 2 , which is consistent with the test results under the uniaxial compression. 


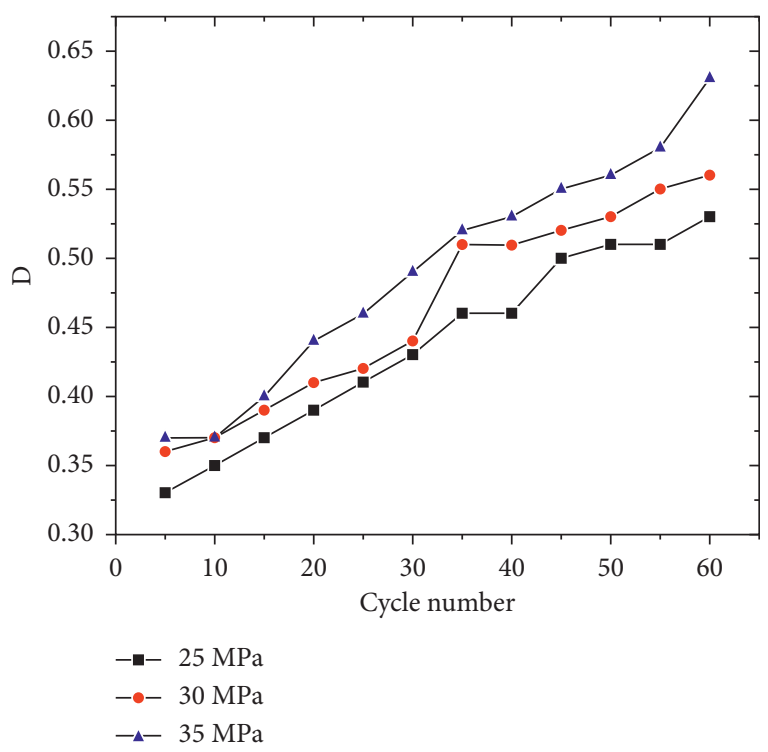

Figure 6: Variation law of damage variable $D$ of the concrete with the cycle number $C$ under different stress amplitudes.

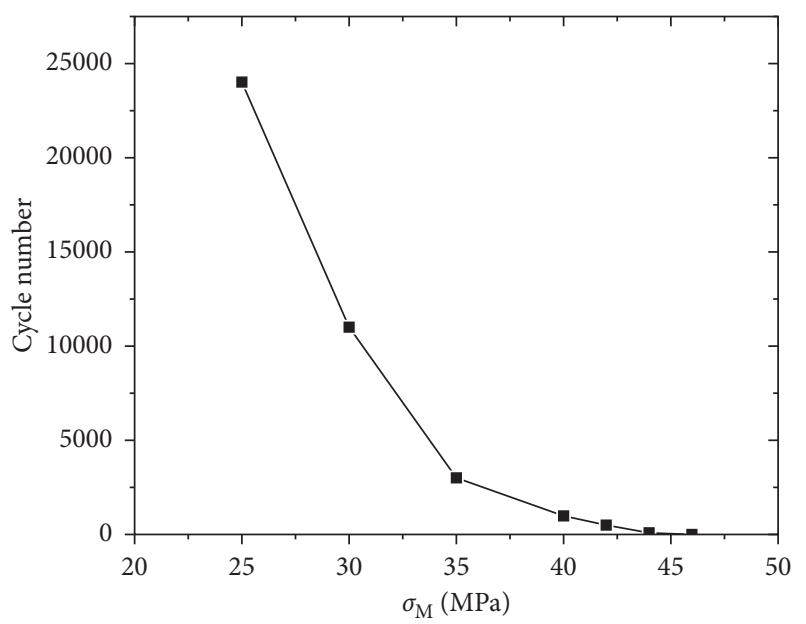

Figure 7: Relation law between cyclic number $C$ and stress amplitude $\sigma_{M}$ of concrete.

\section{Conclusions}

In this study, the universal testing machine was used to load and unload the concrete samples with the porosity of $15 \%$ under different stress amplitudes in the displacement loading mode. The effects of the changes of stress amplitude and cycle number on the mechanical properties and energy dissipation of high-porosity concrete were analyzed. The main conclusions are as follows:

(1) A total of 60 cyclic loading and unloading tests are carried out under three stress amplitudes, and the variation law of the cyclic loading and unloading stress-strain curves of concrete is obtained. The stress-strain curves of concrete under the stress amplitude of $25 \mathrm{MPa}$ are changed from sparse to dense; the stress-strain curves of concrete under stress amplitudes of $30 \mathrm{MPa}$ and $35 \mathrm{MPa}$ are changed from sparse to dense and then sparse.

(2) The influence of stress amplitude variation on the mechanical properties of concrete is mainly reflected in the following aspects: under the three stress amplitudes, the loading and unloading elastic modulus of concrete first increases and then decreases, and the greater the stress amplitude, the faster the growth and deceleration of elastic modulus; the peak strain and residual plastic deformation increase gradually with the increase of the cycle number, and the greater the stress amplitude, the greater the peak strain and residual plastic deformation at the same cycle number; the greater the stress amplitude, the greater the dissipation energy of concrete under the same cycle number, and the variation law of concrete under the three stress amplitudes is roughly the same.

(3) The greater the stress amplitude, the higher the damage of concrete. With the increase of cyclic loading and unloading times, the damage of concrete becomes larger and larger. When the damage variable value is 1, the relationship between the cycle number and the initial stress amplitude satisfies a negative exponential function. When the stress amplitude is $54 \mathrm{MPa}$, the number of concrete cycles is 1 .

\section{Data Availability}

The data used to support the findings of this study are included within the article.

\section{Conflicts of Interest}

The authors declare that they have no conflicts of interest.

\section{Acknowledgments}

This research was funded by the National Key Research and Development Program of China (2019YFC1904302) and China Energy Group Science and Technology Program (GJNY-20-111).

\section{References}

[1] J. Liu, "Review on durability of permeable concrete pavements from the perspective of sponge city," Journal of Jiangsu College of Engineering and Technology, vol. 16, no. 4, pp. 20-23, 2016.

[2] J. Jiang, Z. Lu, Y. Niu, J. Li, and Y. Zhang, "Study on the preparation and properties of high-porosity foamed concretes based on ordinary Portland cement," Materials \& Design, vol. 92, pp. 949-959, 2016.

[3] K. Yu, D. Li, H. Yuan et al., "“Sponge city:” theory and practice," City Planning Review, vol. 39, no. 6, pp. 26-36, 2015.

[4] D. Ma, H. Duan, Q. Zhang et al., "A numerical gas fracturing model of coupled thermal, flowing and mechanical effects," Computers, Materials \& Continua, vol. 65, no. 3, pp. 2123-2141, 2020. 
[5] D. J. Cook and P. Chindaprasirt, "Influence of loading history upon the compressive properties of concrete," Magazine of Concrete Research, vol. 32, no. 111, pp. 89-100, 1980.

[6] D. J. Cook and P. Chindaprasirt, "Influence of loading history upon the tensile properties of concrete," Magazine of Concrete Research, vol. 33, no. 116, pp. 154-160, 1981.

[7] S. Akutagawa, F. L. Jeang, N. M. Hawkins, B. M. Liaw, J. Du, and A. S. Kobayashi, "Effects of loading history on fracture properties of concrete," ACI Materials Journal, vol. 88, no. 2, pp. 170-180, 1991.

[8] S. Xing, L. Wan, T. Deng et al., "Uniaxial compressive properties of concrete under the cyclic load," Chinese Journal of Underground Space and Engineering, vol. 4, no. 2, pp. 281-284, 2008.

[9] D. Ma, J. Wang, X. Cai et al., "Effects of height/diameter ratio on failure and damage properties of granite under coupled bending and splitting deformation," Engineering Fracture Mechanics, vol. 220, Article ID 106640, 2019.

[10] H. Hu, G. Peng, J. Xie et al., "Experimental study on dynamic compressive behaviors of concrete due to circular loading history," Concrete, vol. 1, pp. 51-54, 2013.

[11] Z. Wang, L. Gao, and J. Lu, "Constitutive model of concrete with uniaxial rate," Journal of Dalian University of Technolgy, no. 5, pp. 597-601, 2000.

[12] H. Liang, G. Peng, S. Zou et al., "Study on stress-strain curve of concrete under cyclic loading," Journal of Civil Engineering and Management, vol. 31, no. 4, pp. 55-59, 2014.

[13] Z. Song, T. Frtihwirt, and K. Heinz, "Inhomogeneous mechanical behaviour of concrete subjected to monotonic and cyclic loading," International Journal of Fatigue, vol. 132, 2020.

[14] D. Ma, H. Duan, J. Liu, X. Li, and Z. Zhou, "The role of gangue on the mitigation of mining-induced hazards and environmental pollution: an experimental investigation," The Science of the Total Environment, vol. 664, pp. 436-448, 2019.

[15] Z. Song, H. Konietzky, and T. Frühwirt, "Hysteresis energybased failure indicators for concrete and brittle rocks under the condition of fatigue loading," International Journal of Fatigue, vol. 114, pp. 298-310, 2018.

[16] D. Ma, J. Zhang, H. Duan et al., "Reutilization of gangue wastes in underground backfilling mining: overburden aquifer protection," Chemosphere, vol. 264, no. 1, Article ID 128400, 2021.

[17] D. Jiang, W. Liu, J. Chen et al., "Fatigue behavior of concrete under graded discontinuous cyclic loading," Journal of Southeast University (Natural Science Edition), vol. 49, no. 04, pp. 631-637, 2019.

[18] J.-Q. Xiao, D. X. Ding, G. Xu, and F. L. Jiang, "Inverted S-shaped model for nonlinear fatigue damage of rock," International Journal of Rock Mechanics and Mining Sciences, vol. 46, no. 3, pp. 643-648, 2009.

[19] K. Rakesh and B. Bhattacharjee, "Porosity, pore size distributionand in situ strength of concrete[J]," Cement and Concrete Research, vol. 33, no. 1, pp. 155-164, 2003.

[20] I. O. Yaman, N. Hearn, and H. M. Aktan, "Active and nonactive porosity in concrete Part I: experimental evidence," Materials and Structures, vol. 35, no. 2, pp. 102-109, 2002.

[21] M. Amianti and V. R. Botaro, "Recycling of EPS: a new methodology for production of concrete impregnated with polystyrene (CIP)," Cement and Concrete Composites, vol. 30, no. 1, pp. 23-28, 2008.

[22] M. Balshin, "Relation of mechanical properties of powder metals and their porosity and the ultimate properties of porous meal - ceramic materials," Doklady Akademii Nauk SSSR, vol. 67, no. 5, pp. 831-834, 1951.

[23] D. P. H. Hasselman and R. M. Fulrath, "Effect of small fraction of spherical porosity on elastic moduli of glass," Journal of the American Ceramic Society, vol. 47, no. 1, pp. 52-53, 1953.

[24] F. P. knudsen, "Dependence of mechanical strength of brittle polycrystalline specimens on porosity and grain size," Journal of the American Ceramic Society, vol. 42, no. 8, pp. 376-387, 1949.

[25] D. Ma, H. Duan, X. Li, Z. Li, Z. Zhou, and T. Li, "Effects of seepage-induced erosion on nonlinear hydraulic properties of broken red sandstones," Tunnelling and Underground Space Technology, vol. 91, Article ID 102993, 2019.

[26] D. Ma, S. Kong, Z. Li, Q. Zhang, Z. Wang, and Z. Zhou, "Effect of wetting-drying cycle on hydraulic and mechanical properties of cemented paste backfill of the recycled solid wastes," Chemosphere, vol. 282, Article ID 131163, 2021.

[27] C. Deng and Z. Li, "Experimental study on mechanical properties of concrete with porosity," Concrete, no. 7, pp. 41-44, 2016.

[28] C. Xia, H. Xie, and J. Yang, "SHPB test on porous rock," Chinese Journal of Rock Mechanics and Engineering, vol. 5, pp. 896-900, 2006.

[29] D. Ma, H. Duan, W. Liu, X. Ma, and M. Tao, "Water-sediment two-phase flow inrush hazard in rock fractures of overburden strata during coal mining," Mine Water and the Environment, vol. 39, no. 2, pp. 308-319, 2020.

[30] Y. Lian, "Design of mix proportion of porous modified concrete and determination of porosity," Transport Standardization, vol. 35, no. 4, pp. 43-46, 2010.

[31] P. Li, Y. F. Wu, Y. Zhou, and F. Xing, "Stress-strain model for FRP-confined concrete subject to arbitrary load path," Composites Part B: Engineering, vol. 163, pp. 9-25, 2019. 